\title{
Editor's Introduction - Guidelines for Submissions to the International Journal of Rural Criminology
}

This is the $4^{\text {th }}$ issue (Volume 2, Issue 2) of the International Journal of Rural Criminology. Slowly, IJRC is growing and its future prospects are bright because so many scholars today are interested in issues related to rural crime and criminal justice. Fully 48 percent of the world's population is rural, and even though population projections indicate that this percentage will decline steadily, there will remain throughout this century billions of people living in thousands of rural localities, with a diversity of cultural, social and economic contexts that rivals if not exceeds the heterogeneity presumed to be a hallmark of the city.

The International Journal of Rural Criminology is an on-line, peer-reviewed journal dedicated to the publication of both theoretical and empirical articles about rural crime. Its perspective is global and the journal will consider any topic that is both criminological and rural in focus. This may include a comparative rural-urban empirical or theoretical focus, however, the primary focus must be rural.

IJRC is an electronically based journal published through the Knowledge Bank of The Ohio State Universities Libraries. All inquiries about possible submissions to IJRC should be made to Joseph F. Donnermeyer, editor, Room 408 C, Kottman Hall, School of Environment and Natural Resources, The Ohio State University, Columbus, Ohio (donnermeyer.1 @ osu.edu or donnermeyer.1@gmail.com; 001-614-292-9167[office] or 0116145824710 [cell]).

Articles in this edition of IJRC include theoretical work (Doucet and Lee - Civic Community Theory and Rates of Violence), a study of heroin use in the Shetland Islands (StallwitzCommunity Mindedness: Protection against Crime in the Context of Illicit Drug Cultures?), agricultural crime and crime prevention in Kenya (Bunei, Rono and Chessa-Crime Prevention on Farms: The Opinions of Farmers), trafficking and abuse of farmworkers (Barrick, Lattimore, Pitts and Zhang - Labor Trafficking Victimization among Farmworkers in North Carolina: Role of Demographic Characteristics and Acculturation), and relationship violence (Maume, Lanier, Hossfeld and Wehmann - Social Isolation and Weapon Use in Intimate Partner Violence Incidents in Rural Areas).

On the next two pages is a statement of guidelines for all future submissions to IJRC. These guidelines follow the format for citations and bibliography which can be found in the journal Critical Crimimology. 


\section{Manuscript Style}

The manuscript should be prepared double-spaced in Microsoft Word. The submission should include the manuscript and all tables and figures in a single Word file.

\section{Title Page}

The title page should include:

(1) A concise and informative title (16 font/bold); and

(2) in 12 font: The name(s) of the author(s); the affiliation(s) and address(es) of the author(s); and the email address, telephone and fax numbers of the corresponding author.

\section{Abstract \\ Please provide an abstract of 100 to 150 words. The abstract should not contain any undefined abbreviations or unspecified references.}

\section{Text Formatting}

Manuscripts should be submitted in Word.

- Use a normal, plain font (e.g., 12-point Times Roman) for text.

- Double space, with an indent to begin each new paragraph

- Use italics for emphasis.

- Use the automatic page numbering function to number the pages.

- Do NOT use field functions.

- Use tab stops or other commands for indents, not the space bar.

- Use the table function, NOT spreadsheets, to make tables.

- Use the equation editor or MathType for equations.

Note: If you use Word 2007, do not create the equations with the default equation editor but use the Microsoft equation editor or MathType instead.

\section{Headings}

Please use no more than three levels of displayed headings.

Primary heading - left justify, 14 font, bold

Secondary heading - indented, 12 font, bold

Tertiary heading - indented, italics, colon after heading, begin paragraph on the same line

\section{Abbreviations \\ Abbreviations should be defined at first mention and used consistently thereafter.}

\section{Endnotes Only/Table Notations}

Do NOT use footnotes or footnote formatting. Instead, use superscript to indicate the number of an endnote and locate all endnotes at the end of the narrative, but before references. Endnotes are to be numbered consecutively. Please use the primary heading of "Endnotes" for this section of your manuscript.

Special notes for tables/figures (such as the significance level of a statistical test) should be indicated by superscript lower-case letters (or asterisks for significance values and other statistical data), and placed at the bottom of the table/figure.

\section{Acknowledgments}

Acknowledgments of people, grants, funds, etc. should be placed in a separate section before the reference list. The names of funding organizations should be written in full.

\section{Citation in text formatting}

Cite references in the text by name and year in parentheses. Some examples:

- Single author citation in text - example: "Thorsten Sellin (1938) articulated the core of criminology as the study of how normative structures and processes influence criminal behaviors."

- Double author citation in text -- example: "While some studies show strong support for the theory, other researchers question both its ability to explain variations in rural crime and the fundamental validity of social disorganisation's assumptions (Donnermeyer and DeKeseredy 2014)."

- For a three or more authors citation in text - For first citation, list all authors - example: "Beggs, Haines and Hurlbert (1996) observed from their survey that when compared with urban respondents, those residing in rural localities had more dense networks of acquaintanceship." For citations thereafter to the same work, list only first 
author, followed by et al - example: "Sociologists have long been interested in the impact of population size on the solidarity of people living in smaller places (Beggs et al 1996)."

- Multiple citations in text - example: "The most prominent advocates of civic community theory for the study of rural crime are Lee and associates (Lee 2008; Lee and Slack 2007; Lee and Thomas 2010; Ousey and Lee 2013).

- For a quoted citation in text - example: "Rural areas tend to have an incomplete, fragmented form of community organization because of problems associated with spatial dispersion in an urban society (Wilkinson 1984, p. 450)."

OR, "Wilkinson (1984, p. 450) observed: quotation here."

\section{Reference list}

The list of references should only include works that are cited in the text and that have been published or accepted for publication. Personal communications and unpublished works should only be mentioned in the text. Do NOT use footnotes or endnotes as a substitute for a reference list. Reference list entries should be alphabetized by the last names of the first author of each work. For references not illustrated by the examples below, consult APA guidelines.

Journal article example:

Carrington, K., A. McIntosh, and J. Scott. (2010). Globalization, frontier masculinities and violence: Booze, blokes and brawls. British Journal of Criminology, 50, 393-413.

doi journal article example

Barclay, E. M. and Donnermeyer J. F. 2009. Crime and security on agricultural operations." Security Journal, 24; 118 doi: $10.1057 /$ sj.2008.23.

Book example:

Weisheit, R. A., Falcone, D. N., \& Wells, L. E. (2006). Crime and policing in rural and small-town America. Long Grove, IL: Waveland Press.

Book (also an Encyclopedia entry) chapter:

Weisheit, R. A., \& Donnermeyer, J.F. (2000). Change and continuity in crime in rural America. In G. LaFree, J. F. Short, R. J. Bursik, Sr., \& R. B. Taylor (Eds.), The nature of crime: Continuity and change. Criminal justice 2000 volume 1 (pp. 309-348). Washington, D.C.: National Institute of Justice. (OR, for electronic access, use web address instead)

Article/information source from the web:

Highlands and Islands Enterprise. (2007). Economic update: Shetland. April 2007. Retrieved15/02/2007 from http://www.hie.co.uk/about-hie/policies-and-publications/default.html.

Article/information from a newspaper/magazine

Standard Newspaper (2013). Why residents sleep a step away from their cattle. Standard Group, Nairobi: 27, Published on $10^{\text {th }}$ August, 2013.

OR, retrieved on-line:

The Guardian (23/04/2008). Heroin death exposes Shetland drugs blight. Retrieved 09/02/09 from http://www.guardian.co.uk/uk/2008/apr/23/scotland.drugstrade.

Thesis/Dissertation

Barclay, Elaine. (2003). Crime within rural communities: The dark side of Gemeinschaft. PhD Dissertation. Armidale, New South Wales: The University of New England. (or, web address if retrieved on-line) 